\title{
El museo en busca de los turistas
}

\author{
Luisa Fernanda Rico Mansard
}

RESUMEN

El presente trabajo se divide en tres partes: consideraciones, reflexiones y propuestas, teniendo como objetivo fundamental el potenciar el uso turístico de los museos en México a partir de la revalorización de los objetos en el ámbito museal, del acercamiento al museo más allá de su entorno inmediato y, sobre todo, con la apreciación del turista, no como integrante del gran público, sino como público meta. Bajo esta óptica se sugiere la museología turística como un campo de análisis específico y su aplicación práctica en beneficio del turista. Se parte de las ideas de alteridad, lo local, lo global y lo glocal como elemento atractor de turistas y se proponen diez acciones operativas para alcanzar estos propósitos.

\section{PALABRAS CLAVE}

Trinomio: museo-turista-mediador, visita museo-turística, museología turística 


\title{
El museo en busca de los turistas
}

\author{
Luisa Fernanda Rico Mansard
}

ABSTRACT

This essay is divided into three parts: considerations, reflections and proposals, taking as the principal objective to promote the use of the tourist museums in México from the beyond of revaluation of the objects in the museum field, and, about all, with the appreciation of the tourist, not as a member or the general public, but as a target audience. In this perspective suggest museology tourism as a field analysis of specific and practical application for the benefit of tourists. It stars from the ideas of otherness, the local, the global and the glocal as an attractor of the tourists and proposes ten operational actions to achieve these purposes.

\section{KEY WORDS}

Trinomial: museum-tourist-mediator, visit museum-tourism, tourist museology. 


\section{PUNTOS DE PARTIDA}

Luisa Fernanda Rico

Mansard

Doctora en Historia.

Docente de las materias:

Patrimonio y uso turístico del patrimonio, Universidad

Intercontinental, Escuela de

Turismo

Línea de Investigación:

implicaciones sociales

$y$ ambientales del

aprovechamiento turístico de

bienes patrimoniales.

e-mail:

r.mansard@hotmail.com

lrico@uic.edu.mx

lfrico@universum.unam.mx
El propósito de este trabajo es el de destacar la necesidad de fomentar el uso turístico de nuestros museos, para lo cual se sugiere construir, dentro de los estudios museológicos, un apartado especial dedicado a los turistas. Una museología turística como campo de estudio específico - de utilidad, tanto para profesionales de museos, como para turismólogos y administradores turísticos-, que aborde las necesidades y expectativas de los viajeros nacionales e internacionales, a fin de integrar las distintas ofertas museales a diferentes programas de turismo cultural, así como a otros programas turísticos alternativos (Bote, 2002; Zamorano, 2002; Ávila, 2007).

Este análisis forma parte de la Línea de Investigación: Implicaciones sociales y ambientales del Aprovechamiento turístico de Bienes patrimoniales, que se desarrolla en la Escuela de Turismo de la Universidad Intercontinental. Tiene como antecedentes teóricos, entre otros: "Propuesta metodológica (etnografía turística) para el estudio interdisciplinario de la experiencia turística en espacios culturales" (Rico, Alucema, 2006), "La experiencia turística en espacios culturales" (Rico, Alucema, 2008) y "Museología y Turismo Cultural en México" (Rico, 2007). La perspectiva histórica de la relación museo - turismo en nuestro país, se trabajó en "Patrimonio Cultural, Museos y Turismo en México. Trayectorias y encuentros" (Rico, 2006). En la práctica, se han hecho varios estudios teórico-prácticos de enfoque cuantitativo y cualitativo, entre otros, en Palacio Nacional de la ciudad de México en los que se han incluido varias técnicas: entrevistas, cuestionarios, análisis de recorridos, poder de atracción de los murales de Diego Rivera, etc..

En virtud de que México posee un rico patrimonio cultural ubicado en más de mil museos a nivel nacional y dado que los museos son para el viajero un 'espacio de encuentro con el destino turístico', con estos estudios se intenta potenciar sus colecciones y sus actividades para volverlas en atractores turísticos. 
Éste no es un análisis acabado, sino que constituye una serie de reflexiones en torno al trinomio: museo-turista-mediador. Es, sobre todo, una invitación para realizar aportaciones desde distintas perspectivas y disciplinas que permitan el cruce de saberes y propicien un entramado interdisciplinario que conduzca a nuestra meta (Castillo y M. Lozano, 2006).

La presentación se divide en tres apartados. El primero, CONSIDERACIONES, destaca la función social del objeto y del objeto musealizado; la dimensión comunicativa del museo y la conveniencia de distinguir al turista como una audiencia específica. El segundo, REFLEXIONES, sugiere una forma de analizar al turista partiendo de tipologías museales y turísticas; el tercero, PROPUESTAS, pone énfasis en la perspectiva patrimonial por destacar en nuestros museos a fin de ponderar los valores glocales de toda comunidad y plantea 10 sugerencias para mejorar el uso turístico de nuestros museos. 


\section{CONSIDERACIONES}

\section{El objeto en el entorno museal.}

UNO DE LOS ESPACIOS FÍSICOS EN QUE SE GUARDA Y SE COMUNICA EL PATRIMONIO TANGIBLE HEREDADO ES, SIN LUGAR A DUDAS, EL MUSEO.

DE HECHO, PODEMOS AFIRMAR QUE EXISTE UNA RELACIÓN DIRECTA ENTRE EL PROCESO DE MUSEALIZACIÓN Y EL DE PATRIMONIALIZACIÓN SOCIAL DE BIENES CULTURALES.

En el momento en que una pieza deja de desempeñar sus funciones originales y se revaloriza para ser preservada para la posteridad, empieza a adquirir un valor agregado especial, mismo que va creciendo, tanto con el paso del tiempo, como por su aceptación social (Bazin, 1969; Ballart, 1997; Ballart y Juan-Treserras, 2001).

La resignificación del objeto musealizado le otorga un plusvalor muy especial, avalado por una institución cultural de fuerte arraigo y reconocimiento social a nivel internacional, el museo. Hay dos maneras básicas de acercamiento a estos objetos:

Por su valor como documento, destacándolo individualmente por su originalidad, singularidad, unicidad, etc., o

Por su valor como cultura material, intentando ofrecer el contexto en que se produjo y los valores sociales que entraron en juego para su elaboración (García, 1988).

Al estar integrado al museo, podemos mirarlo también como elemento de un producto museográfico específico. El objeto se convierte en pieza sustantiva para comprender el discurso expositivo, ya que ha sido rescatado, revalorizado y reinterpretado en un contexto museal, para su apreciación pública. Aquí hay que incluir también a los equipamientos científicos, materiales u obras de arte creados expresamente para un diseño museográfico. El carecer de la pátina del tiempo no desmerita su valor $y$, sin embargo, hay que destacarlos por su intencionalidad inicial y su función dentro de la concepción museográfica. Su valor científico, estético o social, o la combinación de éstos, pueden ser en sí mismos muy atractivos. 
Vistos de manera tradicional, los museos son sólo repositorios, bodegas, escaparates, lugares de culto "a la memoria y el olvido"(Morales, 1996: Alonso, 1999); acervos en manos de algunos curiosos y cuidadores, que carecen de significado para buena parte de la sociedad. Con todo y ello no hay que descartar que estos thesaurus siguen teniendo hasta la fecha un encanto especial. Muchos turistas, sobre todo los que cuentan con una amplia cultura museal, no pierden la oportunidad de visitar el conjunto de monedas o los especimenes de historia natural desfilando uno tras otro en los gabinetes antiguos o en grandes y pesadas vitrinas. En la actualidad y ante los embates de la modernidad, el ofrecer estos museos de época no como bodegas, sino como productos culturales propios de un periodo histórico, se apunta hacia la recuperación de visitantes.

Pero hoy en día hay que encarar otros retos. Los medios masivos de comunicación, las nuevas tecnologías y los procesos de globalización económica y cultural nos obligan a cambiar estas perspectivas tradicionales e ir más allá de la mera apreciación de piezas y colecciones como elementos sueltos. No se trata de quitar los objetos o cambiar todas las museografías (volver lo antiguo moderno o viceversa), sino de revalorizarlos buscando un equilibrio entre el producto del pasado y las exigencias de la actualidad, así como encontrar la mejor manera de ofrecerlos al turista:

En primera instancia y tal y como lo reafirma el Movimiento Internacional de la Nueva Museología (MINOM) hay que pensar las piezas en su nuevo entorno. No como producto acabado, sino como proceso social, que va desde el valor inherente de cada objeto a su reconceptualización en el museo. La intencionalidad y el discurso museográficos del conjunto de piezas o colecciones en exhibición.

En segundo lugar, no concebir al museo como custodio o mero contenedor de colecciones, sino como un territorio cultural que traspasa sus propios muros; como una manifestación cultural integral de una comunidad que tiene mucho que ofrecer al visitante (Alonso, 1999; Casasola, 2002).

En tercer lugar, pensar los acervos bajo una perspectiva patrimonial: como producto social específico heredado y/o revalorizado por otra comunidad. 


\section{Comunicación en museos.}

LOS MUSEOS, COMO COMUNICADORES DE MENSAJES, SE DEBEN HOY EN DÍA, MÁS A SUS PÚBLICOS, QUEA SUS PIEZAS.

Es bajo la perspectiva de la comunicación museal donde se da la interacción entre el objeto, el mensaje, el discurso museográfico, los animadores y uno o más visitantes.

Pero, ¿qué tipo de visitantes?, ¿Es válida todavía la idea del Gran Público de los museos, en donde sólo se piensa la atención al turista a través de textos, audioguías o la mediación en otro idioma?

Si una de las grandes metas de la museografía es lograr transmitir a "toda la gente" sus mensajes de manera formal y amena, el uso de lenguajes sencillos y accesibles (lecto-escritura, visual, auditivo, etc.) bastarían para cumplir su cometido. Aunque así se ha hecho pensando preferentemente en el público escolar, no es suficiente (Rico, 2004).

Sin hacer a un lado las exigencias educativas, hay que reconocer que el museo posee varias opciones comunicativas que se deben explotar para otras audiencias específicas. Entre ellas:

- El valor polisémico de las piezas.

- El valor patrimonial de las piezas.

- La capacidad de conjuntar y combinar varios medios de comunicación hasta convertirse, en sí mismo en un multimedio.

- La posibilidad de convertir el espacio museal en un espacio social.

- La posibilidad de ofrecer desde un trato personalizado 'cara a cara', hasta el trato virtual a través de las nuevas tecnologías.

Cada una de ellas o la mezcla de varias permite pensar a los visitantes de distinta manera. Si bien, hoy en día se tiende a manejar estos aspectos en niños y adolescentes, no cabe duda que su aplicación al turista tiene un espectro más amplio. La cuestión en este caso radica en concebir al turista como audiencia específica (Hooper, 1994; Diamond, 1999, Pérez, 2000;) insertarlo en programas museales especiales y potenciar el turismo cultural. 


\section{El turista como audiencia específica del museo.}

\section{EL FLÂNNEUR Y EL TURISTA EN EL MUSEO.}

Si comparamos a los grandes públicos de los museos en México, podemos dividirlos grosso modo en escolar y en paseante-turista.' El escolar está ya profusamente tipificado, mientras que el segundo no. Fuera de la perspectiva educativa de enseñanza formal, no formal e informal, los museos mexicanos no se han ocupado en incursionar en otros parámetros demográfico-sociales, desconociendo características básicas, como: el origen, el idioma, la ideología, las necesidades, las expectativas, las experiencias museales, etc. de los demás visitantes y, en consecuencia, sus intereses y su probable inserción en programas socioculturales, de turismo cultural y turismo científico, entre otros.

En cuanto al museo se refiere, el problema es más serio en el momento en que ni siquiera podemos distinguir al turista del flânneur o residente de la localidad que gusta de "turistear" en los museos durante los fines de semana o en algunas horas de descanso. Y no porque se quiera insertar al flânneur -importante consumidor cultural- en las categorías preestablecidas de turista, sino simplemente porque el flânneur es un turista cultural en potencia. Dado que una buena experiencia museística (Falk y Dierking, 1992) insita a visitar museos dentro y fuera del lugar de residencia, es crucial que los museos conozcan más a fondo a este tipo de público, aprovechen sus intereses culturales y procuren su asistencia.

Desde el extremo opuesto, pocos turistólogos y administradores turísticos no sólo no saben lo que es tener una experiencia museística agradable, sino que desconocen la oferta de museos y salas de exhibición de su lugar de residencia (y fuera de él también) y las distintas formas de acercarse al museo. La carencia de análisis críticos al respecto queda en detrimento del uso del museo en programas de turismo cultural, de negocios, alternativo, etc.

El turista cultural, por regla general, tiende a ser un visitante que:

- Está interesado en ir al museo y de éste aprovecha el entorno, el edificio, la temática de exhibición, los contenidos. 
- Puede considerársele como un "ciudadano cultural" en la medida en que está en la posibilidad de decidir libremente lo que quiere ver y cómo lo quiere ver, la ruta por seguir, el tiempo dedicado a los objetos, vitrinas, tiempos de descanso, etc. y es capaz de mirar objetos y leer las cédulas sin necesidad de depender de una mediación.

- Asiste libremente sin condiciones de tiempo.

- Está dispuesto a pagar por la entrada.

- Es una persona dispuesta a encontrarse con sorpresas.

- Busca servicios museales adicionales.

El museo para el turista, representa una gran oportunidad de conocer:

- En un espacio reducido

- En un tiempo corto, y

- A través de diferentes lenguajes,

lo más importante de un destino turístico o lo más apreciado en ese momento. Por tal motivo, hay que tener consideraciones especiales, acordes a sus características:

- Dentro de los servicios básicos, requiere atención en su idioma (cédulas, imágenes, videos, audioguías, catálogos, folletos,etc.)

- Necesita que se le trate como adulto en un sentido democrático.

- Requiere de varias formas de interpretación del discurso museográfico.

- Ofrecerle una experiencia museística especial.

EL MUSEO ES EL ESPACIO DE ENCUENTRO Y DE INTERACCIÓN DEL TURISTA CON EL DESTINO TURÍSTICO. 


\section{REFLEXIONES}

Como hemos visto, la atractividad museal depende en buena medida del contenido, del continente, los entornos y los servicios que se ofrecen al público. Pero eso no garantiza la visita turística. En los turistas encontramos una extensa gama de intereses que van desde quienes tienen un gran capital cultural y gran interés en los museos, hasta quienes no sólo no les interesa lo cultural o los museos, sino que, incluso, los aborrecen. Su experiencia museística ha sido tan pobre y aburrida que sólo pensar en ellos les causa malestar. Entre estos viajeros destacan muchos adolescentes y adultos.

No se trata de que prevalezca la situación existente, sino de potenciar el uso turístico de los museos. Si, por un lado, en el museo, los Departamentos de Servicios Educativos, Servicios al Público o de Comunicación Educativa y actualmente de Gestión del Patrimonio² se abocan a sus públicos "tradicionales" y deben abrir su especto a otras audiencias como la del turista, las personas dedicadas al turismo deben hacer lo propio y enfocar su mirada a la visita museo-turística.

ES NECESARIO SABER MÁS SOBRE NUESTROS TURISTAS PARA REFLEXIONAR EN FORMAS MEJORES Y MÁS DIVERSIFICADAS DE ATENDERLOS y, por qué no pensar en un grupo, departamento u oficina dedicada especialmente al turista.

Por un lado, hay que agregar a las evaluaciones demográficas, cognitivas y conductuales que los museos hacen sobre sus visitantes, las categorías que interesan el sector turístico: origen, idioma, tipo de turismo, nicho de mercado, actitudes, conductas, etc, y hacer análisis cuantitativos, cualitativos y transversales con aportes interdisciplinarios.

Por el otro, crear o completar tipologías de turismo cultural ajustándolas a la oferta museal (por audiencias, temas museográficos, etc.) y, en su caso, proponer categorías o subcategorías nuevas.

El entramado de estas redes de información y conocimientos nos debe conducir a análisis críticos y reflexivos, así como abordarlo como problema epistemológico en la construcción de la museología turística. 
Sabido es que nuestros museos no cuentan con personal suficiente para desempeñar sus actividades normales con éxito. Por ello, sugiero que DENTRO DE LOS PROGRAMAS DE ESTUDIO SOBRE MUSEOS Y EN LAS CARRERAS RELACIONADAS CON TURISMO SE INCLUYAN ESPECÍFICAMENTE TEMAS CULTURALES, PATRIMONIALES, DE MUSEOS Y COLECCIONES, ANALIZANDO SU USO TURÍSTICO. 


\section{PROPUESTAS}

Tanto los museos, como la inserción de los objetos en los mismos, han respondido a esquemas europeos, intentando ofrecer interpretaciones que satisfagan a grandes públicos. Ello devino en la pérdida de información, de valores y de sentidos sociales de las piezas. A esta situación -que duró cerca de 500 años en México-, podemos sumar el actual influjo de los mass media, las nuevas tecnologías y los procesos de globalización económica y cultural de las últimas décadas.

Aunque con la creación de los museos comunitarios, los ecomuseos y el movimiento de la Nueva Museología -de los años 70 y 80- se intentó disminuir los efectos de la globalización cultural, estas acciones no han sido suficientes. Hay que tomar en cuenta que si la experiencia museística sólo intentara el mostrar objetos, éstos pueden apreciarse muy bien -a veces mejor- a través de la Internet y no habría necesidad de turistas en los museos. Por ello hay que REPENSAR NUESTROS MUSEOS BAJO LA MIRADA DEL TURISTA Y QUÉ MEJOR QUE ECHAR MANO DE LAS IDEAS DE LA ALTERIDAD.

El conocimiento y reconocimiento de la "otredad" en tiempo y espacio sigue en espera de su expansión:

... los bienes y servicios culturales que, en la medida en que son portadores de identidad, de valores y sentido, no deben ser considerados como mercancías o bienes de consumo como los demás, sino respetarse por su diversidad (Declaración Universal de la UNESCO sobre la Diversidad Cultural, 2001, Art. 8).

Dentro de la creación y la consolidación de industrias culturales hay que respetar y proteger los conocimientos y las prácticas culturales tradicionales, especialmente los de las poblaciones autóctonas; reconocer la contribución de los conocimientos tradicionales a la protección del medio ambiente y a la gestión de los recursos naturales, y favorecer las sinergias entre la ciencia moderna y los conocimientos locales (Ibid., Art.14)

Los museos han de desempeñar un papel más fuerte con relación al patrimonio intangible, para volver a inyectar vida a su patrimonio tangible. Potenciar más lo local dentro de los movimientos 
globalizadotes (Scheiner, 1998, 2000): ASUMIR LO GLOCAL, TANTO PARA GENERAR UN EQUILIBRIO ENTRE LO GLOBAL Y LO LOCAL, Y PARA DESTACAR LA DISTINCIÓN DE COLECCIONES Y MUSEOS $M E X I C A N O S$. Asumir una dimensión integral y holística de nuestro trabajo museal recupera los elementos de nuestra riqueza cultural, misma que puede ofrecerse a visitantes de distintas partes del mundo.

En este sentido hay que anotar que el Consejo Internacional de Museos (ICOM), sensible a este problemática, pone énfasis en la sensibilización al valor del patrimonio dentro de su Plan Estratégico de acción 2008-2010 (Our Global Vision, 2007), por lo que podemos suponer que será una tendencia de trabajo a nivel mundial.

Para que todo esto aterrice en acciones más prácticas, propongo considerar los siguientes propósitos:

1. Propiciar análisis críticos y reflexivos que aborden el problema epistemológico para la construcción de la museología turística en México.

2. Insertar en los estudios y servicios museológicos existentes las ideas de educación informal, de animación cultural y de edutenimiento dirigidos para turistas.

3. Involucrar a turistólogos, administradores turísticos, prestadores de servicios turísticos en las actividades de los museos.

4. No reducir el servicio al turista sólo a proporcionar la visita en otro idioma.

5. Agregar en los contenidos de la visita turística el proceso de musealización (desde el descubrimiento, rescate, preparación, investigación y concepciones museográficas).

6. Propiciar una perspectiva patrimonial y de sustentabilidad, tanto de los contenidos, como de los entornos del museo.

7. Involucrar al turista afectivamente con las actividades de los museos y en las necesidades de conservación y preservación de bienes culturales tangibles e intangibles. (El turista como actor).

8. Insertar la visita museística como una experiencia turística en sentido amplio. (experiencia museística, modelo pull-push, etc.) 
9. Crear propuestas museo-turísticas novedosas (edades, temas, culturas, etc.)

10. Integrar a los museos con mayor peso dentro del turismo cultural y en otros programas turísticos. 


\section{BIBLIOGRAFÍA}

- Alonso, L. (1999), Introducción a la Nueva Museología, Madrid, Alianza Editorial.

- Ávila, R.,( 2007), Turismo Cultural en México: alcances y perspectivas, México, Trillas.

- Ballart, J., (1997) El Patrimonio Histórico y arqueológico, valor y uso, Barcelona, Ariel, (Ariel Patrimonio Histórico).

- Ballart, J. y J. Juan-Tresserras, (2001), Gestión del Patrimonio Cultural, España. Ariel.

- Bazin, G., (1969), El Tiempo de los Museos, Trad. Casanova Viamonte y M.D. Massor Gimeno, Barcelona, Ediciones Daimon.

- Bote, V., (2002), Planificación económica del turismo. De una estrategia masiva a una artesanal, México, Trillas.

- Cárdenas, F., (1997), Comercialización del Turismo. Determinación y análisis de mercados, $5^{a}$. Edición, México, Trillas.

- Cárdenas, F., (2001), Proyectos turísticos. Localización e inversión, México, Trillas.

- Casasola, L., Turismo y ambiente, 2a . Edición, México, Ed. Trillas.

- Castillo M. y M. Lozano, (2006), Apuntes para la investigación turística, México, Universidad de Quintana Roo-CAT.

- Diamond, J., (1999), Practical Evaluation Guide. Tools for museums and other informal educational settings, USA, Altamira Press.

- García, A., (1988) Didáctica del Museo,: el descubrimiento de los objetos, Madrid, de la Torre.

- Hooper, E., (1994), Museums and their visitors, London, Ed. Roudledge.

- Morales, L., (1996), "Qué es un museo", en Cuicuilco, Revista de la Escuela Nacional de Antropología e Historia, Nueva Época, Vol. 3, ním. 7, pp.59-104.

- ICOM-UNESCO, (2007), Nuestra visión global. En pro de un mundo en el que se valore universalmente la importancia del patrimonio natural y cultural.

- Pérez, E. ([2002]), Estudios de visitantes en museos: metodologías y aplicaciones, Ediciones Trea. 
- Rico, L., (2003), "Una mirada turística al Museo Nacional de Antropología", en Revista Intercontinental Ducit et Docet de Investigación, México, UIC, Vol. IV, Núm 1, pp. 3743.

- Rico, L., (2004), "Museos Mexicanos. Usos y desusos" en Correo del Maestro. Revista para Profesores de Educación Básica, México, Uribe y Ferrari Editores, Año 8, Núm. 93, 2004, pp. 23-43.

- Rico, L., (2006), "Patrimonio Cultural, Museos y Turismo en México. Trayectorias y encuentros", en Patrimonio Cultural y Turismo, Cuadernos 14 Planeando sobre el turismo cultural, México, CONACULTA.

- Rico L. y Alucema, M., (2006) "Propuesta metodológica (etnografía turística) para el estudio interdisciplinario de la experiencia turística en espacios culturales", conferencia presentada en el VIII Congreso Nacional y $2^{\circ}$ Internacional de Investigación Turística, SECTUR, Tecnológico de Monterrey, 14 junio 2006.

- Rico L., (2007), "Museología y Turismo Cultural en México", Conferencia presentada en el IX Congreso Nacional y III Internacional de Investigación Turística, CESTUR, Colima, 21 septiembre 2007.

- Scheiner, T., (1998) "Museología, globalismo y diversidad cultural", en VII Encuentro Regional, ICOFOM LAM 98 Museos, museología y diversidad cultural en América Latina y el Caribe, México.

- Scheiner, T., (2000), "Museología, identidades, desarrollo sustentable: Estrategias discursivas", en Gaceta de Museos, órgano informativo del Centro de Documentación Museológica, México, CONACULTA-INAH, jul.-dic. 2000 pp. 109-125.

- Zamorano, F., (2002), Turismo alternativo. Servicios turísticos diferenciados, México, Trillas, 2002. 


\section{CITAS}

' Los estudios de público en museos destacan muchas categorías de público, como el adulto o el familiar. En este caso hacemos referencia a estos dos segmentos (escolar y paseanteturístico) por considerarlos como importantes nichos de mercado. Ambos son muy numerosos y poseen características propias y necesidades homogéneas, que hay que cubrir dentro de una oferta general de mercado.

${ }^{2}$ Modelo de servicio de la mayor parte de nuestros museos. En especial a los que dependen del Instituto Nacional de Antropología e Instituto Nacional de Bellas Artes. 


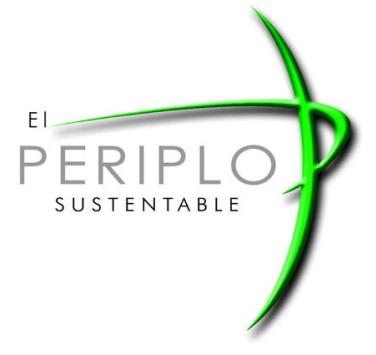

FICHA BIBLIOGRAFICA:

Rico-Mansard, L. F. El museo en busca de los turistas. El Periplo Sustentable. Espacio de análisis y reflexión sobre Turismo Sustentable. México: Universidad Autónoma del Estado de México, julio de 2008, núm. 14

$<$ http://www.uaemex.mx/plin/psus/rev14/articulo_02.pdfs. [ISSN: 1870-9036]. 